\title{
CONSTRUÇÃO DE UM PROTÓTIPO DE TÚNEL DE VENTO E AVALIAÇÃO DA UTILIZAÇÃO DE EQUIPAMENTOS PARA AULAS PRÁTICAS DE MECÂNICA DOS FLUIDOS
}

DOI: 10.37702/2175-957X.COBENGE.2021.3637

Arthur Gomes da Silva Vilaronga - arthur.vilaronga@yahoo.com

Faculdade Nobre de Feira de Santana

Rua Cruz e Souza 143

44001-064 - Feira de Santana - BA

Igor Melo Guimarães - igor.m.guimaraes@hotmail.com

Faculdade Nobre de Feira de Santana

Rua Palmerim 45

44065-666 - Feira de Santana - BA

Renata Velasques Menezes - renatavelasques.ufrb@gmail.com

Unidade Superior de Ensino de Feira de Santana

Rua Itaúna 109

44090-308 - Feira de Santana - BA

Wylliane Lustosa viera - wyllianelustosa@gmail.com

Faculdade Nobre de Feira de Santana

Rua Juíz de Fora 154

44052-052 - Feira de Santana - BA

Resumo: Os túneis de vento podem ser utilizados dentro de projetos e atividades que simulem uma didática menos tradicional, servindo como suporte para o desenvolvimento de aulas práticas, já que o Ministério da Educação defende a utilização de metodologias cada vez mais inovadoras, como o ensino mediante projetos acadêmicos. Portanto, este trabalho tem como objetivo desenvolver um modelo de túnel de vento em escala reduzida, de modo que fique disposto para conciliação com os conceitos abordados em sala no decorrer do ensino da componente curricular Mecânica dos Fluidos na Unidade de Ensino Superior de Feira de Santana, e avaliar se o desenvolvimento de aulas práticas contribui para uma forma de aprendizagem mais didática nesta componente curricular. Para isto, após a pesquisa para uma aproximação com o tema, iniciou o processo de 
desenvolvimento do protótipo, com detalhamento de suas partes individuais no software de desenvolvimento computacional, SolidWorks, versão de 2017, para posterior montagem. Após a finalização do desenho, o protótipo físico foi montado a partir de peças de MDF, colas instantâneas, e uma caixa de acrílico utilizada como seção de testes. Com a construção do protótipo, para reforçar a importância de se ter um túnel de vento equipando os laboratórios da instituição, foi feita uma entrevista quantitativa e qualitativa, avaliando a relevância de aulas práticas dentro da Mecânica dos Fluidos. Foi percebido que para uma melhor aprendizagem da componente, é relevante a utilização do túnel de vento, onde os discentes podem assimilar melhor alguns temas como o estudo da camada limite, as características do escoamento e desperte o senso de criatividade nos alunos através da observação destes fenômenos. A disponibilização do equipamento também permitirá o desenvolvimento de projetos que se relacionem com aerodinâmica, conforto térmico, melhorias em protótipos.

Palavras-chave: Metodologias ativas, engenharia, dinâmica de fluidos, aerodinâmica. 


\section{CONSTRUÇÃO DE UM PROTÓTIPO DE TÚNEL DE VENTO E AVALIAÇÃO DA UTILIZAÇÃO DE EQUIPAMENTOS PARA AULAS PRÁTICAS DE MECÂNICA DOS FLUIDOS}

\section{INTRODUÇÃO}

A simulação computacional e a utilização da instrumentação são duas importantes ferramentas que auxiliam na resolução de problemas dentro do campo da engenharia (BEZERRA, 2017). São aplicadas tanto para facilitar a visualização de fenômenos físicos quanto na melhoria de produtos e processos já desenvolvidos, através de ensaios de laboratórios, como por exemplo nos estudos aerodinâmicos.

Aerodinâmica é a ciência que estuda o comportamento dos fluidos (líquido ou gás) em um dado objeto, onde se considera suas propriedades e características, e o conjunto de forças atuantes neste corpo (RODRIGUES, 2014). Dentro do setor automobilístico, por exemplo, é importante avaliar o comportamento do vento quando um automóvel está em movimento. Na construção civil, o vento influencia exercendo pressão sobre as estruturas e na arquitetura, no conforto térmico (SHIMOMURA; FROTA; CELANI, 2010).

Frente a esta necessidade, em 1871, o britânico Frank H. Wenham desenvolveu o primeiro modelo de um túnel de vento, mas somente 1900, através dos irmãos Wright a utilização de um túnel de vento ganhou mais relevância (NASA, 2014). A NASA (2014) afirma ainda que, com a construção de seu primeiro planador tripulado sem motor, os irmãos Wright, após constatarem que o planador não tinha tanta sustentação, realizaram testes com ventos naturais para comparação com as forças de levantamento.

Testes em túneis de vento objetivam um escoamento forçado e controlado do vento sobre um objeto. Este objeto deve ser dimensionado em escala reduzida. Para garantir a precisão dos ensaios no sentido de prever o comportamento em escala real, algumas similaridades precisam ser estabelecidas através de três números adimensionais: 0 número de Reynolds, o número de Mach e o número de Froude (BARLOW, 1999).

Dentro dos estudos de mecânica dos fluidos, todos esses coeficientes adimensionais são introduzidos, assim como todos os fenômenos que envolvem os estudos da dinâmica dos fluidos. Os túneis de vento podem ser utilizados dentro de projetos e atividades que simulem uma didática menos tradicional, tirando a concepção do docente como detentor do conhecimento e trazendo uma característica de tutor da construção do saber (ROCHA, 2019).

Desta forma, os discentes se aproximam cada vez mais de abordagens mais práticas, já que o Ministério da Educação (2018) tem defendido um perfil do egresso do curso de engenharia cada vez mais instigador, pesquisador. Estas atividades experimentais estão associadas a metodologias ativas que contribuem positivamente para o desenvolvimento da autonomia por parte dos discentes no processo de aprendizagem (ROCHA, 2019).

Há seis objetivos chave para a utilização de laboratórios e métodos experimentais na educação, sendo eles a familiarização, a identificação do modelo, a validação de hipóteses (comprovação experimental de pressupostos), os testes de conformidade, a previsão do comportamento de sistemas complexos e a exploração de novas informações (NJOCK-LIBII, 2011).

O MEC (2018) defende a utilização de metodologias cada vez mais inovadoras, como o ensino mediante projetos acadêmicos, a aprendizagem baseada em problemas (PBL), e os laboratórios de engenharia da instituição de ensino (IES) em questão 
precisam estar preparados para o desenvolvimento destes projetos, com equipamentos como um Túnel de Vento para estudos de aerodinâmica, por exemplo.

Neste contexto, a utilização de um túnel de vento dentro dos estudos de dinâmica dos fluidos possivelmente contribuirá para um processo de aprendizagem mais ativo. Portanto, esse projeto tem como objetivo desenvolver um modelo de túnel de vento em escala reduzida, de modo que fique disposto para conciliação com os conceitos abordados em sala no decorrer do ensino de Mecânica dos Fluidos em uma IES de Feira de Santana e avaliar se o desenvolvimento de aulas práticas contribui para uma forma de aprendizagem mais didática na componente curricular.

\section{METODOLOGIA}

\subsection{O desenho}

Inicialmente, foi feita uma pesquisa bibliográfica sobre túneis de vento em artigos científicos e livros, maioritariamente em produções virtuais disponíveis na internet em sites acadêmicos. A principal plataforma de busca utilizada foi o Google Acadêmico, mantendo a pesquisa restrita a aplicações didáticas e métodos de construção de protótipos. As publicações que tratavam de dimensionamento do equipamento em tamanho real, ou utilização de túneis de vento para modelagem, foram descartadas.

A partir desta pesquisa, foram definidas as principais produções de consulta obedecendo ao critério de afinidade com a abordagem proposta por este trabalho e foram identificadas também as obras consideradas clássicas que abordam a temática de túneis de vento. Os livros foram mais utilizados neste processo, por constituírem uma maior amplitude conceitual básica.

Após a pesquisa para uma aproximação com o tema, iniciou o processo de desenvolvimento do protótipo, com detalhamento de suas partes individuais no software de desenvolvimento computacional, SolidWorks, versão de 2017, para posterior montagem.

O primeiro elemento desenhado foi a área de testes, pois o dimensionamento depende da aplicação, ou seja, as proporções do equipamento dependem do que será estudado nesta área. O desenho foi feito em plano direito e com a ferramenta de retângulo central, foram definidas as dimensões $175 \times 250 \mathrm{~mm}$ baseado no modelo de Coutinho (2014).

$\mathrm{Na}$ aba de recursos, foi utilizada a ferramenta de ressalto/base extrudado para expandir a vista frontal com um cumprimento de $300 \mathrm{~mm}$ também referenciado no projeto de Coutinho (2014). Em seguida, utilizando a ferramenta de cascas, deixando espessura de $6 \mathrm{~mm}$ (dimensão escolhida empiricamente), a seção de testes foi perfurada.

A partir de uma razão de área de 2 (definido empiricamente), foi encontrado o cumprimento de $600 \mathrm{~mm}$ através de (3) tanto do bocal quando do difusor. Foi utilizado um ângulo equivalente de 5․

Onde,

$$
L=R 1 \cdot \frac{A R^{1 / 2}-1}{\tan \theta_{e}}
$$

$\mathrm{R} 1=$ metade da altura menor do bocal $(12,5 \mathrm{~cm})$;

$\mathrm{AR}=$ razão de área;

$\theta_{e}=$ ângulo equivalente.

Para o bocal e o difusor, foi feita uma geometria semelhante à seção de testes, mas com $600 \mathrm{~mm}$ de comprimento. O comprimento foi encontrado através da razão de 
área. Depois, com a ferramenta de inclinação na aba de recursos, a partir da face, foi feita uma inclinação de $5^{\circ}$ referente ao angulo de equivalência em toda a peça. Com todas as peças desenhadas, foi feita a montagem no software como pode ser vista na figura $2 a \mathrm{e}$ $2 b$.

Figura 2a e 2b - Túnel de Vento Didático
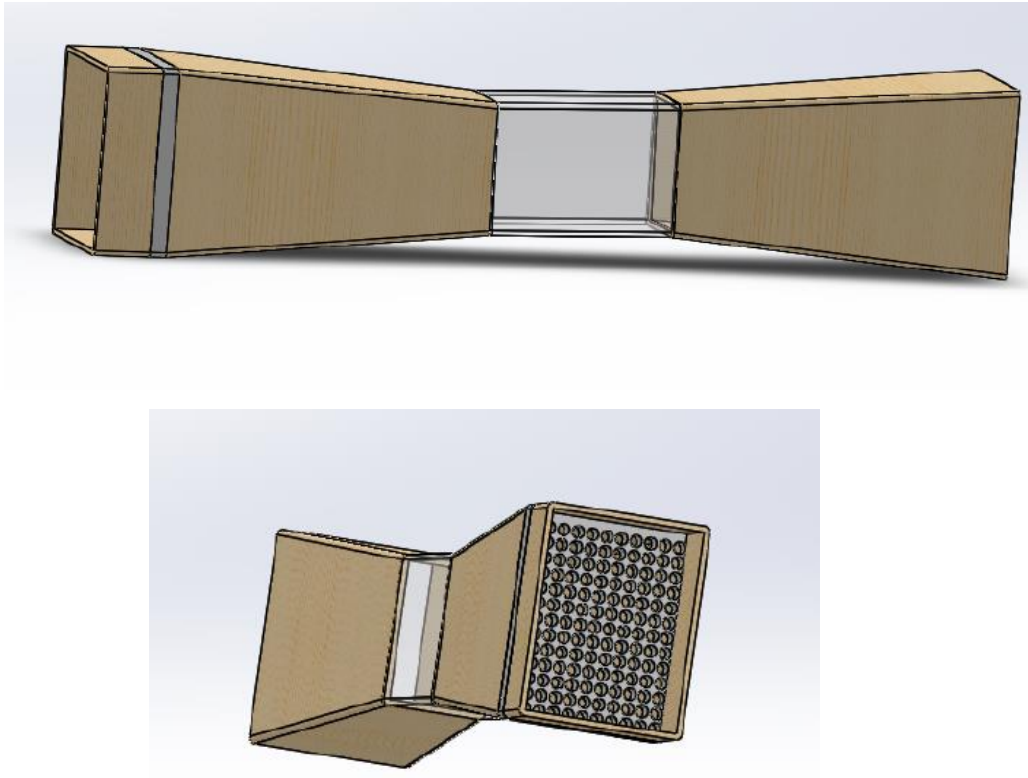

\subsection{O protótipo físico}

Fonte: autoria própria.

Para a construção do túnel de vento, foram utilizadas 8 peças de MDF, figura 3 , cujas dimensões podem ser vistas na figura 4 , com encaixe de $6 \mathrm{~mm}$ para facilitar a montagem. Também foi feita uma caixa de acrílico para a seção de testes com uma tampa para possibilitar o posicionamento do objeto a ser estudado.

Figura 3 - Peças de MDF

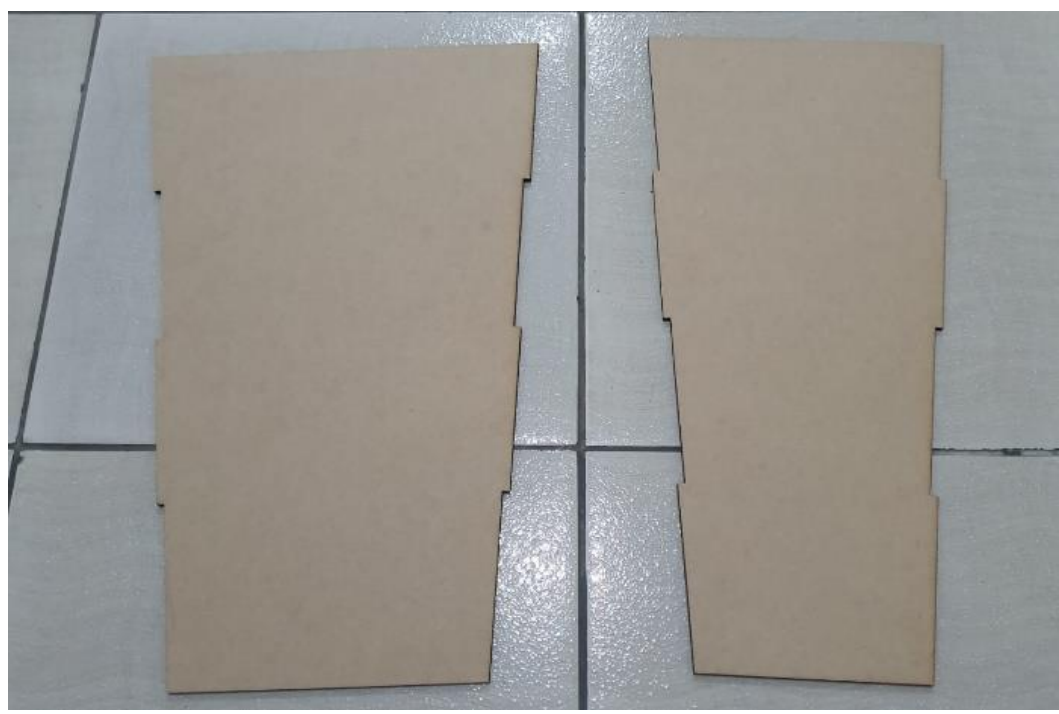


Fonte: autoria própria.

Figura 4 - Desenho da peça superior

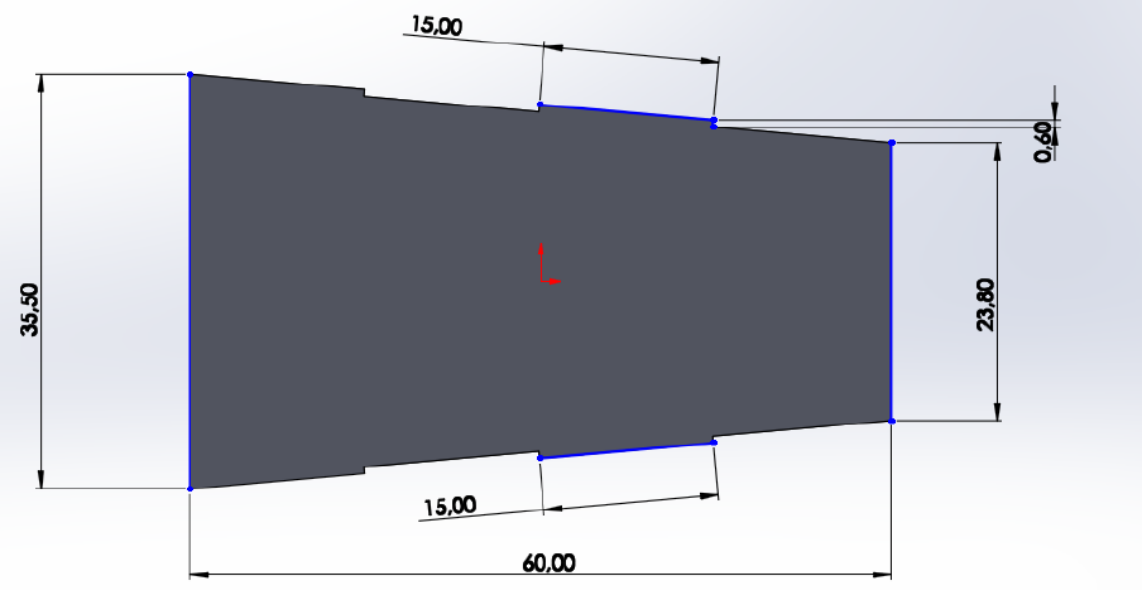

Fonte: autoria própria.

Para confecção das partes do túnel de vento, foi utilizada cola instantânea devido a sua boa capacidade de firmar e por proporcionar um acabamento melhor se comparado a outros elementos de fixação. Para este processo, foram adquiridas quatro colas 6 colas instantâneas.

A primeira parte a ser produzida foi o difusor que, para montagem (figura 5 e 6), foram necessárias 3 colas de 2 gramas. Estas colas foram passadas nos encaixes, tendo as peças sido apoiadas numa parede para garantir um bom nivelamento entre elas.

Figura 5 - Desenho da peça lateral

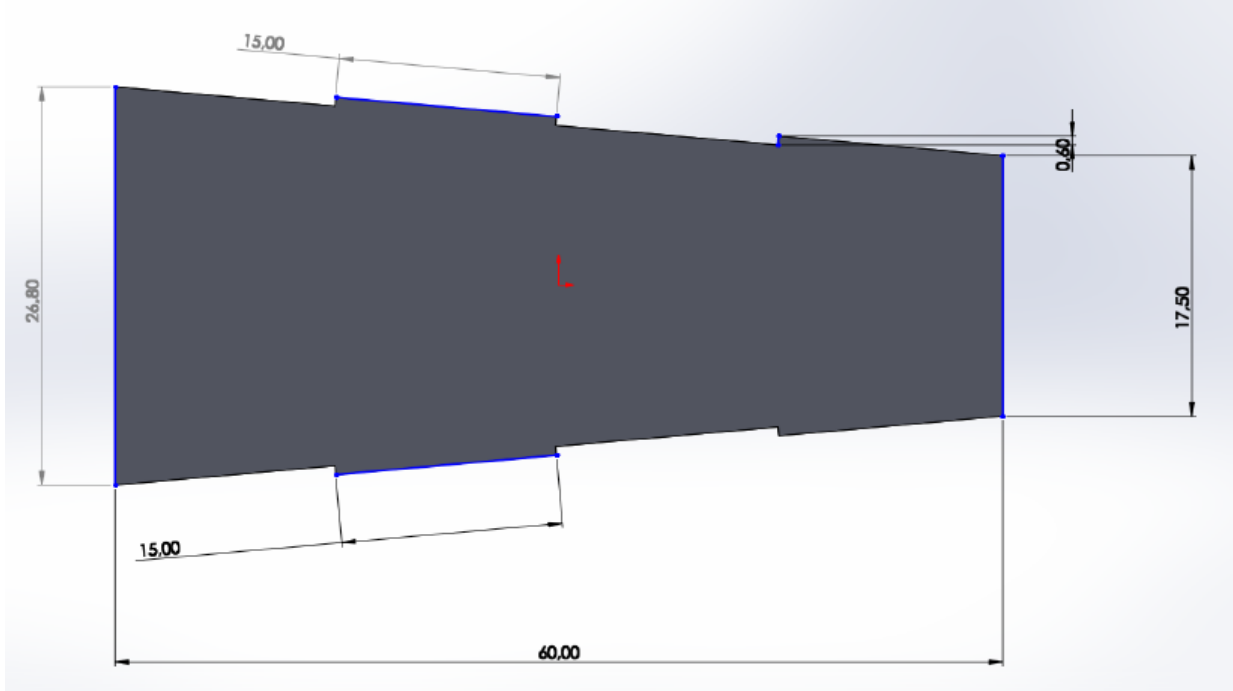

Fonte: autoria própria.

Com esta etapa finalizada, foi feito o bocal de acordo com a mesma metodologia da produção do difusor. Para este, foi necessário a utilização de uma cola de 2 gramas e parte do tubo de 85 gramas. O bocal e o difusor podem ser vistos na figura 7 .

Após a secagem, foi verificado se as peças estavam bem seguras para a continuidade da montagem. Tendo esta verificação sido positiva, a seção de testes foi 
acoplada ao bocal e após secagem desta, o difusor foi colado na outra extremidade da caixa de acrílico.

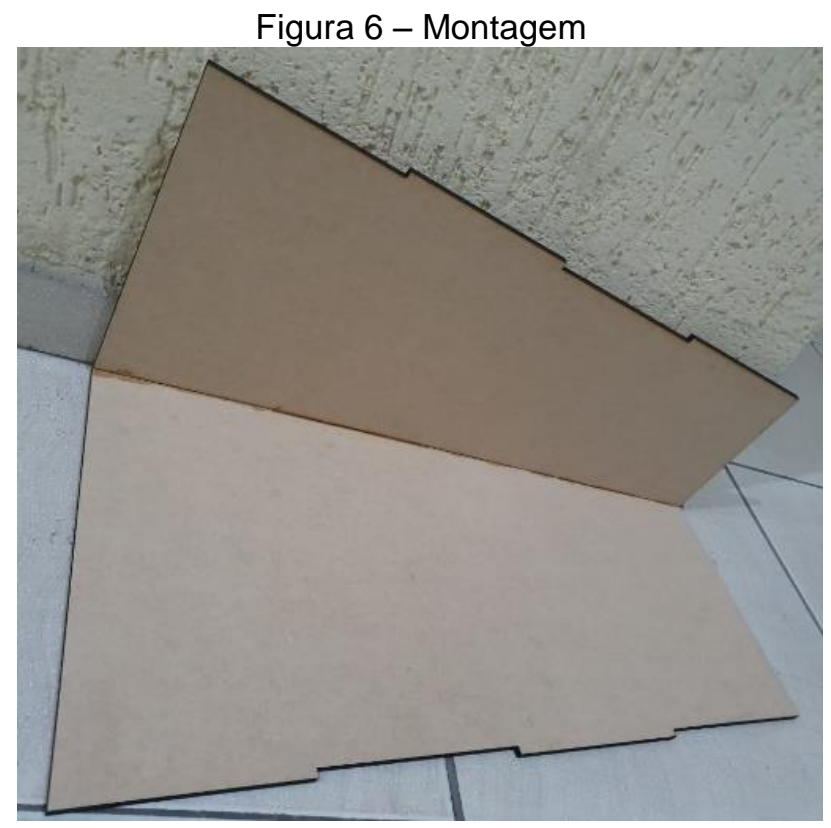

Fonte: autoria própria.

Figura 7 - Bocal e Difusor

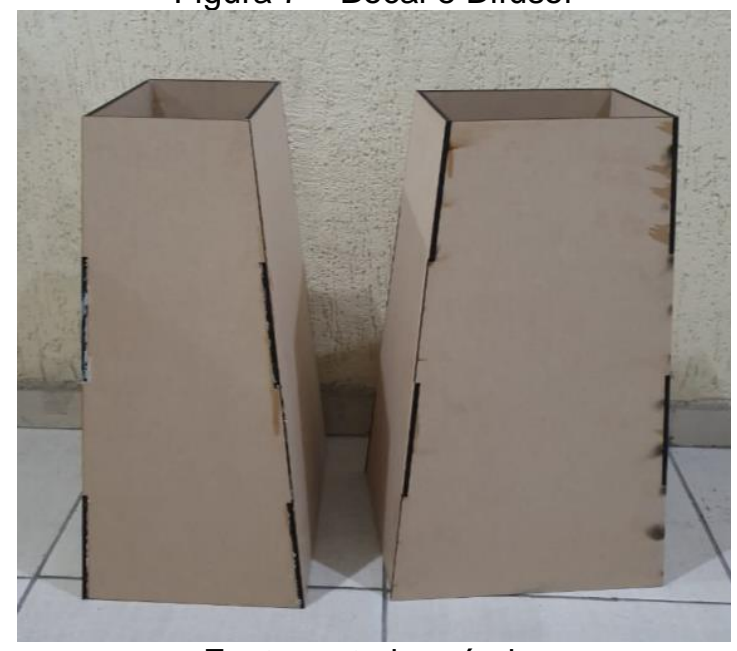

Fonte: autoria própria.

Com a estrutura principal montada, foram cortados 12 rolos de papel higiênico ao meio para a construção da colmeia (Figura 8) que serve para garantir o escoamento laminar na seção de testes. Estas 24 partes foram dispostas de forma que ocupassem 0 interior do bocal.

O ventilador utilizado foi do tipo convencional com dimensões de 30 centímetros de diâmetro, 3 pás e $50 \mathrm{~W}$ de potência. Foram retiradas as proteções para melhorar o encaixe com o túnel de vento, reduzindo as perdas de fluxo de ar na entrada do difusor. $O$ protótipo finalizado pode ser visto na figura 13.

Figura 8 - Colmeia 


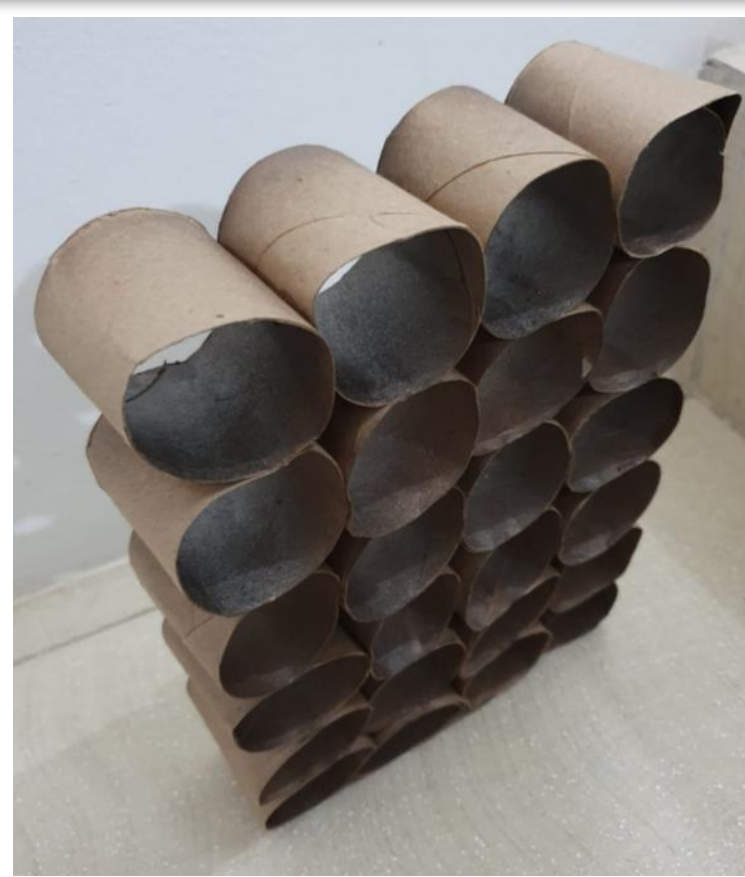

Fonte: autoria própria.

Figura 9 - Protótipo do Túnel de Vento

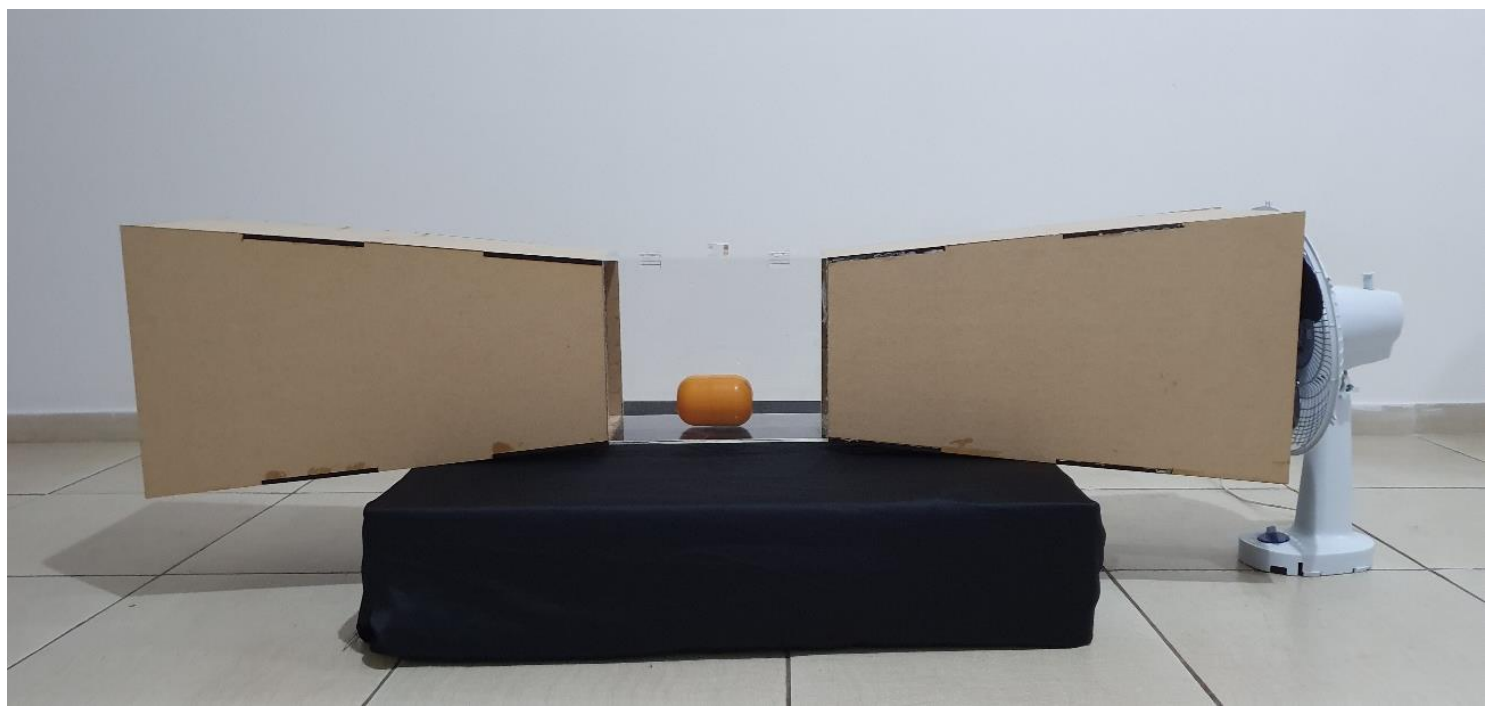

Fonte: autoria própria.

\subsection{Coleta de dados}

Para reforçar a importância de ter um túnel de vento equipando os laboratórios da instituição, foi feita uma entrevista quantitativa e qualitativa avaliando a relevância de aulas práticas dentro da Mecânica dos Fluidos.

Foi utilizado o aplicativo "Forms App" desenvolvido pela plataforma da Google, e disponibilizado gratuitamente nas plataformas Android, iOS e desktop. Esta plataforma possibilitou que os estudantes respondessem por meio de um link que foi disseminado pelas redes sociais dos estudantes dos cursos de engenharias. Assim, em tempo real, o aplicativo nos notificava cada vez que o questionário era respondido, além de disponibilizar um relatório completo e gráficos das respostas. 
Após coleta dos dados por meio do "Forms App", foi gerada uma planilha no software Excel. Os resultados obtidos foram sistematizados em categorias e posteriormente plotados gráficos pelo mesmo software.

\section{RESULTADOS E DISCUSSÃO}

Dos seis cursos de engenharia da instituição, apenas discentes de Engenharia Mecânica (EM), Engenharia Civil (EC) e Engenharia Química (EQ) participaram do questionário, pois, atualmente (período letivo de 2019.2) são os únicos cursos da instituição que possuem a disciplina mecânica dos fluidos, como parte obrigatória em sua grade curricular.

A maioria dos alunos que participaram da pesquisa são egressos do curso de Engenharia Mecânica sendo 63\%, seguido de Civil, representando 22\%, e 15\% de Química. Quando comparado estes resultados com o percentual dos alunos que cursaram a disciplina, no período letivo de 2019.2 (54\% EC, 33\% EM e apenas 13\% de EQ) podese observar uma baixa resposta dos discentes de EC, frente aos de EM. Este resultado se dá pela facilidade de contato com os discentes de EM, pois, os autores da pesquisa são egressos do mesmo curso. Quanto aos discentes de $E Q$, a baixa adesão ao questionário pode ser atribuída ao número reduzido de alunos comparado aos demais cursos, além de ser um dos mais recentes na instituição.

Sobre a importância de atividades práticas como complemento ao ensino, foi unânime, entre os discentes de todos os cursos, que as mesmas contribuem para o seu desempenho acadêmico. Este resultado reflete a necessidade cada vez maior que os profissionais da educação possuem de buscar novos métodos de ensino que contribuam para transformar as práticas discentes, de forma que estes construam possibilidades de atuação e aprendizado nas IES. Ainda, são importantes respostas ao uso de metodologias ativas (MA), como prática de ensino.

Segundo Paiva et al., (2016) as MA tem sua importância como potenciais ferramentas para os profissionais da educação em diferentes áreas do conhecimento que buscam romper com modelos de ensino tradicional e eliminar os efeitos colaterais deste.

A distribuição quanto às graduações cursadas de alunos que participaram da pesquisa foi desproporcional. 74\% afirmaram cursar o componente curricular, enquanto $26 \%$ ainda não cursaram. Desta maneira, os resultados seguintes são trabalhados quanto aos alunos que cursaram ou não as disciplinas.

Foi perguntado aos alunos, ainda, se as instituições em questão proporcionam atividades práticas suficientes para um melhor desempenho acadêmico dos docentes. Segundo dados obtidos, as aulas práticas ainda são insuficientes para $78 \%$ dos alunos enquanto apenas $22 \%$ demonstraram satisfação neste quesito.

Apesar de todos os discentes afirmarem que as aulas práticas contribuem para a construção do conhecimento a respeito dos conteúdos abordados em sala, $65 \%$ dos alunos de EC acreditam que elas não são feitas suficientemente, $56 \%$ dos alunos de $E Q$ afirmam o mesmo. A situação é ainda mais acentuada entre os discentes de EM (33\%). O resultado pode ter sido influenciado pela recente aquisição das bancadas didáticas, que são novos equipamentos para auxiliar as aulas práticas em determinadas componentes curriculares. Por exemplo, o componente curricular Mecânica dos Fluidos, foi recentemente comtemplada com tais equipamentos. Desta forma, alguns destes alunos não tiveram contato com as mesmas, para esta disciplina.

A aprendizagem se dá de maneira mais eficiente com a participação ativa do sujeito que se aprende, ou seja, a partir da vivência experiencial. Esta ideia converge com perfil do engenheiro defendido pelo MEC (2018), um perfil instigador, deixando de lado 
uma metodologia tradicional onde o docente era o sujeito do processo de ensinoaprendizagem. Desta forma, a instituição precisa investir em aulas mais experienciais.

Pekelman e Mello Jr (2004) acreditam que os laboratórios nos cursos de engenharia simulam situações reais e aproximam o discente da ciência e tecnologia servindo ainda como treinamento para a criatividade dos alunos para que possam utilizála para sanar as necessidades humanas quando adentrarem o mercado de trabalho.

Professores submetidos a um questionário a respeito da utilização dos materiais didáticos afirmaram que esses tipos de materiais pedagógicos ampliam o entendimento dos assuntos, há uma maior motivação durante a execução das atividades pedagógicas, materializa os assuntos abstratos e auxilia na fixação dos conceitos matemáticos confirmando assim que os usos de materiais didáticos são importantes para o desenvolvimento cognitivo, competências e experiências de aprendizagem (BOTAS; MOREIRA, 2013).

Desta forma, é perceptível que há uma necessidade cada vez maior que docentes invistam em aulas mais práticas e as instituições de ensino superior (IES) ofereçam suporte para seu corpo docente e discente, com os laboratórios e equipamentos como o túnel de vento. Há também que se considerar que muitos destes equipamentos de baixo custo e alta relevância, possam ser construídos e assim avaliados pelos próprios discentes, como por exemplo, um túnel de vento para visualização dos conceitos estudados em Mecânica dos Fluidos.

A Mecânica dos Fluidos é considerada pelos discentes uma componente complexa e estes consideram de grande relevância as aulas experienciais para conciliar a teoria e prática. Desta forma, para os estudos de escoamento, grupos adimensionais como o número de Reynolds, camada limite, aerodinâmica a utilização do túnel de vento contribuiria para aulas mais dinâmicas.

O conceito de camada limite é relativamente abstrato. Portanto, é de difícil associação com a prática e por isto é importante que seja visto fisicamente para que os discentes visualizem os principais fenômenos que dizem respeito a este tema de forma lúdica, proporcionando uma maior retenção do conteúdo.

Grando (2000) afirma que a ludicidade é essencial ao ser humano, independente da faixa etária, e nos acompanha cotidianamente pois nos é uma necessidade desenvolver uma atividade cujo prazer seja na própria atividade. Vygotsky, psicólogo e pesquisador russo, acreditava que o processo de aprendizagem parte da interação entre o homem e o meio social em que ele vive (LAPA, 2017).

Quanto ao índice de relevância das aulas práticas no componente curricular Mecânica dos Fluidos, $82 \%$ dos alunos avaliaram como nota máxima (escala de 5 - índice de maior satisfação) e apenas 1\% com nota mínima (escala de 1 - que representa menor satisfação). Estes resultados conferem diferentes graus de relevância as aulas práticas, apesar da unanimidade em reconhecer a importância das mesmas. Assim, pode-se inferir que, a abordagem metodológica de estudos confere as aulas prática e/ou expositivas diferentes relevâncias.

Figura 10 - Índice de relevância de aulas práticas para os que já cursaram Mecânica dos Fluidos 


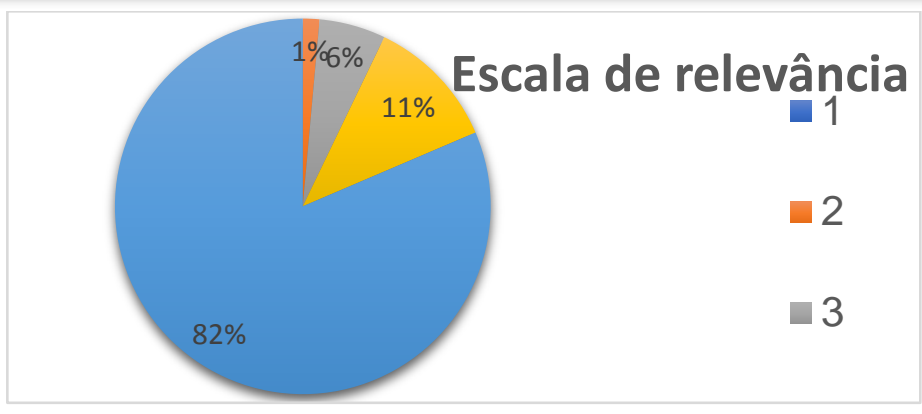

Fonte: autoria própria.

\section{CONCLUSÃo}

O questionário foi capaz de reforçar a importância das aulas expositivas dentro dos temas de física, conforme os entrevistados afirmaram. A ciência se fez a partir de percepções na natureza, portanto visualizar os conceitos estudados teoricamente, fisicamente, é mais eficiente do que manter o processo de aprendizagem centralizado no docente, que deve passar a ser um mediador do conhecimento.

A física utiliza de métodos matemáticos para quantificar os fenômenos, mas a física nada mais é do que a interpretação destes fenômenos. Portanto, cursos com os de engenharia que possuem as ciências exatas como base, especialmente a física, precisam de aulas mais experienciais e menos expositivas para que os discentes visualizem os conceitos estudados de forma teórica, como eles de fato acontecem no cotidiano.

Um laboratório preparado contribui para o fomento à pesquisa, desenvolvimento de projetos melhor elaborados e resultados mais fidedignos, podendo resultar em relevantes descobertas, além de contribuir também para a reprodução de fenômenos de forma lúdica, fomentando a fixação do conteúdo abordado e a associação prática e teórica, podendo auxiliar para reduzir a evasão dos alunos na componente curricular, tal como nos cursos de engenharia.

\section{REFERÊNCIAS}

BARLOW, Jewel; RAE, William; POPE, Alan. Low Speed Wind Tunnel Testing. 3aㅡ. ed. New York:John Wiley \& Sons, 1999.

BEZERRA, Francisco Diego Vidal. Otimização e Instrumentação de um Túnel de Vento. Trabalho de conclusão de curso (Bacharelado em Engenharia Mecânica) Universidade Federal do Ceará, Fortaleza, 2017. Disponível em:

<http://www.repositorio.ufc.br/handle/riufc/31748>. Acesso em: 22 abr. 2019.

BOTAS, Dilaila; MOREIRA, Darlinda. A utilização dos materiais didáticos nas aulas de Matemática: Um estudo no 1ํ Ciclo. Rev. Port. de Educação, Braga , v. 26, n. 1, p. 253286, 2013

Disponível em:

<http://www.scielo.mec.pt/scielo.php?script=sci_arttext\&pid=S0871-

91872013000100010\&lng=pt\&nrm=iso >. Acesso em 16 dez. 2019.

COUTINHO, Felipe Rodrigues. Projeto de um Túnel de Vento Subsônico do Tipo Soprador. Universidade Federal do Rio de Janeiro, 2014. Disponível em: 
$<$ http://monografias.poli.ufrj.br/monografias/monopoli10012170.pdf>. Acesso em: 20 abr. 2019.

GRANDO, Regina Célia. O conhecimento matemático e o uso de jogos na sala de aula. 2000. 224 f. Tese de Doutorado em Educação - Faculdade de Educação. Universidade de Campinas, Campinas, São Paulo.

LAPA, Luis Dionísio Paz. A ludicidade como ferramenta no processo de ensinoaprendizagem da Matemática. 2017. Trabalho de conclusão de curso (Mestrado em Matemática) - Universidade de Brasília, Brasília, 2017. Disponível em: <https://repositorio.unb.br/bitstream/10482/25220/1/2017_Lu\%C3\%ADsDion\%C3\%ADsio PazLapa.pdf>. Acesso em: 15 dez. 2019.

MEC. Diretrizes Curriculares Nacionais para O Curso de Graduação Em Engenharia. Disponível em: <http://portal.mec.gov.br/docman/agosto-2018-pdf/93861-texto-referenciadcn-de-engenharia/file>. Acesso em 17 mar. 2019.

NASA. Whirling Arms and the First Wind Tunnels. Disponível em: <https://www.grc.nasa.gov/www/k-12/WindTunnel/history.html>. Acesso em 15 mar. 2019.

NJOCK LIBII, Josué. Wind Tunnels in Engineering Education. IntechOpen, [S. I.], 27 jul. 2011. DOI 10.5772/17071. Disponível em: <https://www.intechopen.com/books/windtunnels-and-experimental-fluid-dynamics-research/wind-tunnels-in-engineeringeducation>. Acesso em: 20 abr. 2019.

PAIVA, Marlla Rúbya Ferreira et al. Metodologias Ativas de Ensino-Aprendizagem: Revisão Integrativa. SANARE - Revista de Políticas Públicas, [s. I.], v. 15, n. 2, p. 145153 , 2016. Disponível em:

<https://sanare.emnuvens.com.br/sanare/article/view/1049/595>. Acesso em: 1 dez. 2019.

PEKELMAN, Helio; MELLO JR, Antônio Gonçalves. A importância dos laboratórios no ensino de engenharia mecânica. XXXII Congresso Brasileiro de Ensino de Engenharia-COBENGE. Brasília, 2004.

ROCHA, Márcia Raquel Rodrigues. As atividades experimentais como meio de promoção da autonomia: como é que a prática de atividades experimentais em sala de aula influencia a autonomia individual e social dos alunos?. Disponível em: <http://hdl.handle.net/10400.26/25716>. Acesso em 25 mar. 2019.

RODRIGUES, Luiz Eduardo Miranda José. Fundamentos da Engenharia Aeronáutica com Aplicações ao Projeto SAE-AERODESIGN: Aerodinâmica e Desempenho. 1. ed. [S. I.: s. n.], 2014. Disponível em: <http://www.engbrasil.eng.br/livros/v1.pdf>. Acesso em: 10 abr. 2019.

SHIMOMURA, Alessandra Prata; FROTA, Anesia Barros; CELANI, Gabriela. Modelos Físicos na Análise de Ventilação Urbana: 0 Uso do Túnel De Vento. Disponível em: $<$ http://forumpatrimonio.com.br/seer/index.php/forum_patrimonio/article/view/43/0>. Acesso em 25 mar. de 2019. 
SILVA, Selênio Feio da; PEDROSO, Lineu José. Interação barragem-reservatório: estudo dos efeitos conservativos e dissipativos. Revista IBRACON de Estruturas e Materiais, v. 12, n. 4, p. 858-873, 2019.

\title{
CONSTRUCTION OF A WIND TUNNEL PROTOTYPE AND EVALUATION OF THE USE OF EQUIPMENT FOR PRACTICAL CLASSES IN FLUID MECHANICS
}

\begin{abstract}
Wind tunnels can be used within projects and activities that simulate a less traditional didactic, serving as support for the development of practical classes, since the Ministry of Education advocates the use of increasingly innovative methodologies, such as teaching through projects academics. Therefore, this project aims to develop a small-scale wind tunnel model, so that it is willing to reconcile with the concepts discussed in the classroom during the teaching of Fluid Mechanics at Unidade de Ensino Superior de Feira de Santana and to assess whether the development of practical classes contributes for a more didactic form of learning in the curricular component. For this, after research to approach the theme, the process of developing the prototype began, with details of its individual parts in the computational development software, SolidWorks, version 2017, for later assembly. After the drawing was completed, the physical prototype was assembled from MDF pieces, instant glues, and an acrylic box that served as a testing section. With the construction of the prototype, to reinforce the importance of having a wind tunnel equipping the institution's laboratories, a quantitative and qualitative interview was carried out, assessing the relevance of practical classes within Fluid Mechanics. It was noticed that for a better learning of the component, the use of the wind tunnel is relevant, where students can better assimilate some themes such as the study of the boundary layer, the flow characteristics and awaken the sense of creativity in the students through the observation of these phenomena. The availability of the equipment will also allow the development of projects related to aerodynamics, thermal comfort, improvements in prototypes.
\end{abstract}

Keywords: Active methodologies, engineering, fluid skills, aerodynamics. 